\title{
Experimental Determination of Viscosities and Densities of Mixtures Carbon Dioxide + 1-Allyl-3-methylimidazolium chloride. Viscosity correlation
}

Joana M. Lopes ${ }^{1}$, Sabine Kareth ${ }^{2}, M^{a}$ Dolores Bermejo ${ }^{1 *}$, Ángel Martín ${ }^{1}$, Eckhard Weidner $^{2}, \mathrm{M}^{\mathrm{a}}$ José $^{\text {Cocero }}{ }^{1}$

${ }^{1}$ High Pressure Process Group, Department of Chemical Engineering and Environmental Technology, University of Valladolid, Spain

${ }^{2}$ Process Technology, Ruhr-University Bochum, 44780 Bochum, Germany

*mdbermejo@iq.uva.es

\begin{abstract}
The effect of viscosity reduction caused by the solubilization of $\mathrm{CO}_{2}$ is studied in order to improve the biomass processing in ionic liquids. To do so, densities and viscosities of the pure ionic liquid 1-allyl-3-methylimidazolium chloride and its mixtures with $\mathrm{CO}_{2}$ up molar fractions of 0.25 and temperatures between 333 and $372 \mathrm{~K}$ have been experimentally determined. Viscosities were correlated as a function of temperature and $\mathrm{CO}_{2}$ molar fractions with an average relative error of $2.5 \%$. The viscosities of other mixtures $\mathrm{CO}_{2}+$ ionic liquids were also correlated for other ionic liquids with an average relative error between 4.4 and 13\%. In general these ionic liquids present a linear decrease of viscosity with $\mathrm{CO}_{2}$ molar fractions up to around 0.5 that is more pronounced at lower temperatures and depends of each ionic liquid, and can reach between 60-100\% viscosi-
\end{abstract}


ty reduction with respect the viscosity of the pure ionic liquid, making the $\mathrm{CO}_{2}$ a promising co-solvent for viscosity reduction in process with ionic liquids.

Keywords: Ionic liquid; Carbon Dioxide; Viscosity; Density; Excess molar volume; 1-allyl3-methylimidazolium chloride;

\section{Introduction}

There is an increasing interest in the use of ionic liquids (ILs) for processing cellulose and other biopolymers [ 1]. However, the high viscosity of ILs, which is greatly increased when they dissolve cellulose, is the main limitation for their use in these processes [ 2]. Imidazolium chlorides, acetates and alkylphosphates can dissolve high amounts of cellulose and other biopolymers, but recently acetates and alkylphosphates has been preferred due to their lower viscosities and melting points [1], while the imidazolium chlorides present higher viscosities. For these reasons, these ILs are sometimes set aside in cellulose processing, even though they are cheaper and more effective than others in cellulose reactions such as hydrolysis [ 3].

It is known that mixing an IL with molecular solvents allows decreasing its viscosity [ 4]. This is also possible when using carbon dioxide $\left(\mathrm{CO}_{2}\right)$ as a co-solvent, which has the advantages of being non-toxic, cheap, and can be easily separated of the IL by depressurization. ILs and $\mathrm{CO}_{2}$ are considered to be a promising media for the development of “green” technology [ 5]. In biphasic mixtures $\mathrm{IL}^{-\mathrm{CO}_{2}}$ at moderate or high pressure, $\mathrm{CO}_{2}$ can dissolve significantly into the IL-rich liquid phase,_up to concentrations as high as $75 \%$ in mol, but no ionic liquid dissolves in the gas phase [ 5],[6]. Nevertheless in the case of imidazolium chloride ionic liquids $\mathrm{CO}_{2}$ solubility is reduced to values round $30-40 \%$ in mol [ 7]. 
So far, only a few viscosity data of mixtures carbon dioxide + IL can be found in literature: Tomida and coworkers determined the viscosities of $\mathrm{CO}_{2}+$ 1-butyl-3methylimidazolium tetrafluoroborate $\left(\right.$ bmimBF$\left._{4}\right)$ [ 8]; $\mathrm{CO}_{2}+$ 1-butyl-3methylimidazolium hexafluorophosphate $\left(\mathrm{bmimPF}_{6}\right) \quad\left[\right.$ 9]; $\mathrm{CO}_{2}+$ 1-hexyl-3methylimidazolium hexafluorophosphate $\left(\mathrm{hmimPF}_{6}\right)$ and $\mathrm{CO}_{2}+$ 1-octyl-3methylimidazolium hexafluorophosphate $\left(\mathrm{omimPF}_{6}\right)+\mathrm{CO}_{2}$ [ 10]; Liu et al determined determined the viscosities of $\mathrm{CO}_{2}+$ 1-butyl-3-methylimidazolium tetrafluoroborate (bmimPF $)_{6}$ [ 11] and Ahosseini et [ 12] al measured the viscosity of mixtures of several ionic liquids of the n-alkyl-3-methyl-imidazolium bis(trifluoromethylsulfonyl)imide family [-mimTf $2 \mathrm{~N}$ ] with $\mathrm{CO}_{2}$. In general, the decrease in viscosity is between 85 and 45 \% for $\mathrm{BF}_{4}$ ILs with $\mathrm{CO}_{2}$ solubilities between 45 and 35\% $\mathrm{CO}_{2}$ in mol [ 8]. For $\mathrm{PF}_{6}$ ILs with $40-45 \%$ in mol $\mathrm{CO}_{2}$ the decrease lies between 80 and $45 \%$ of the density of the pure IL [ 9],[ 10]. For the $\mathrm{Tf}_{2} \mathrm{~N}$ ILs which present solubilities of $\mathrm{CO}_{2}$ sometimes as high as $90 \%$ the decrease in viscosity can reach $100 \%$ [ 12] at moderate pressures of 10-12 MPa, but with molar fractions as low as $10 \%$ of $\mathrm{CO}_{2}$ decrease of $30-40 \%$ of the pure IL viscosity is already observed. In all cases the effect in viscosity reduction with $\mathrm{CO}_{2}$ is more remarkable at lower temperatures.

There are much more data of densities of mixtures $\mathrm{CO}_{2}+\mathrm{ILs}$, including the systems: $\mathrm{CO}_{2}+$ methylimidazolium hexafluorophosphates ionic liquids [ 9], [ 10]; $\mathrm{CO}_{2}+1-$ ethyl-3-methylimidazolium ethylsulphate [ 13]; $\mathrm{CO}_{2}+$ imidazolium bis[(trifluoromethyl)sulfonyl]imide and triflate ILs [ 14] ; $\mathrm{CO}_{2}+$ 1-ethyl-3methylimidazolium diethyl phosphate, $\mathrm{CO}_{2}+$ 1-ethyl-3-methylimidazolium hydrogen sulfate [ 15], to mention only a few of them. In general densities present little change with increasing $\mathrm{CO}_{2}$ concentration in the ionic liquid, meaning that these systems present considerable lower volume expansions than those of common organic solvents [ 
13], [ 14], [ 16]. This has been interpreted as a consequence of the $\mathrm{CO}_{2}$ is dissolving in the ionic liquid by occupying the bulk free space in the molecule, as confirmed by atomistic simulation [ 17], [ 18] and through Raman spectroscopy [ 19]. As a consequence, large negative molecular volumes are found, due to the lack of expansion of the ionic liquids and the big difference in molecular mass between the ILs and the $\mathrm{CO}_{2}[$ 13].

In this work the viscosities and densities of pure 1-Allyl-3-methylimidazolium chloride (AmimCl) and several $\mathrm{CO}_{2}+\mathrm{AmimCl}$ mixtures were experimentally determined at temperatures between 333 and $372 \mathrm{~K}$ and pressures between 1 and $7 \mathrm{MPa}$, comprising $\mathrm{CO}_{2}$ concentrations between 5 and 25\% in mol. Using density data, excess molar volumes were calculated. Viscosity data were correlated and, in order to test the correlation, viscosity data of other $\mathrm{CO}_{2}+$ ILs mixtures from literature were correlated showing average deviations from 2 to $13 \%$.

\section{Experimental Section}

\subsection{Materials}

The ionic liquid used in this work was 1-allyl-3-methylimidazolium chloride, [Amim][Cl], purchased from Iolitec (Germany), with a purity higher than 98\%. The water contents were determined by Karl-Fischer volumetric titration (Metrohm $870 \mathrm{KF}$

Titrino Plus) obtaining 0.59\% ww in water. Carbon dioxide (99.9\% purity) was supplied by Yara and was used without further purification.

\subsection{Apparatus}

To determine the densities and viscosities a tuning fork vibration viscosimeter was used (Solartron Viscosimeter 7827). In the ranges of viscosities determined the precision was 
$\pm 1 \mathrm{mPa} \cdot \mathrm{s}$ in the range $1-100 \mathrm{mPa} \cdot \mathrm{s}$ and of $\pm 10 \mathrm{mPa} \cdot \mathrm{s}$ in the range $100-1000 \mathrm{mPa} \cdot \mathrm{s}$. Density was determined with a precision of $\pm 1 \mathrm{~kg} \cdot \mathrm{m}^{-3}$. The viscosimeter worked inside of a $1.7 \mathrm{~L}$ pressure vessel able to stand $200^{\circ} \mathrm{C}$ and $20 \mathrm{MPa}$. Temperature in the gas phase was determined with a thermocouple type $\mathrm{K}$ and in the liquid phase (where the tuning fork was situated) with a Pt100. A signal converter Solartron 7946 able to work in the $\mathrm{T}$ range $\left(-200-200^{\circ} \mathrm{C}\right)$ was used with a resolution of $0.1^{\circ} \mathrm{C}$ and a maximum error of $\pm 0.3^{\circ} \mathrm{C}$. Temperature was kept constant by using a circulating bath Lauda Proline P5. Pressure was determined with WIKA type S-11 pressure transmiter with an accuracy of 1 bar $(0.25 \%$ of the span (0-400 bar)).

\subsection{Experimental procedure}

The ionic liquid was charged in the pressure vessel and kept at $90^{\circ} \mathrm{C}$ at vacuum in order to reduce the water content for $8 \mathrm{~h}$. In these conditions the density and viscosities of the pure ionic liquids were determined. After that $\mathrm{CO}_{2}$ was charged in the pressure vessel and the system was equilibrated before determining the viscosity and density. Then the temperature and_pressure were changed in order to determine new experimental points. After finishing all the measurements the water content was determined by Karl Fischer titration.

\section{Results and Discussion}

\subsection{Density and viscosity of the pure ionic liquid}

Densities and viscosities of the pure ionic liquid as a function of temperature are listed in Table 1. In Figure 1 data were plotted together with literature data [ 20], [ 21], [ 22]. It is observed that both, density and viscosity decrease with increasing temperature and that the data determined in this work were consistent with literature data . 
Table 1. Densities and viscosities of 1-allyl-3methylimidazolium chloride determined under vacuum.

\begin{tabular}{ccc} 
T/K & Viscosity/mPa·s & Density/kgm \\
& & \\
\hline 307.0 & 790 & 1141 \\
\hline 311.7 & 530 & 1138 \\
\hline 319.9 & 280 & 1133 \\
\hline 330.0 & 150 & 1127 \\
\hline 337.1 & 100 & 1123 \\
\hline 347.3 & & 1110 \\
\hline 361.1 & 61 & \\
\hline 373.2 & 35 & \\
\hline
\end{tabular}

Viscosity precision $\pm 1 \mathrm{mPa} \cdot \mathrm{s}$ in the range $1-100 \mathrm{mPa} \cdot \mathrm{s}$ and $\pm 10 \mathrm{mPa} \cdot \mathrm{s}$ in the range 100-1000 mPa·s. Density was determined with a precision of $\pm 1 \mathrm{~kg} \cdot \mathrm{m}^{-3}$. Temperature maximum error of $\pm 0.3^{\circ} \mathrm{C}$. Water molar fraction of $\mathrm{AmimCl}\left(\mathrm{x}_{\mathrm{H} 2 \mathrm{O}}=0.497\right)$
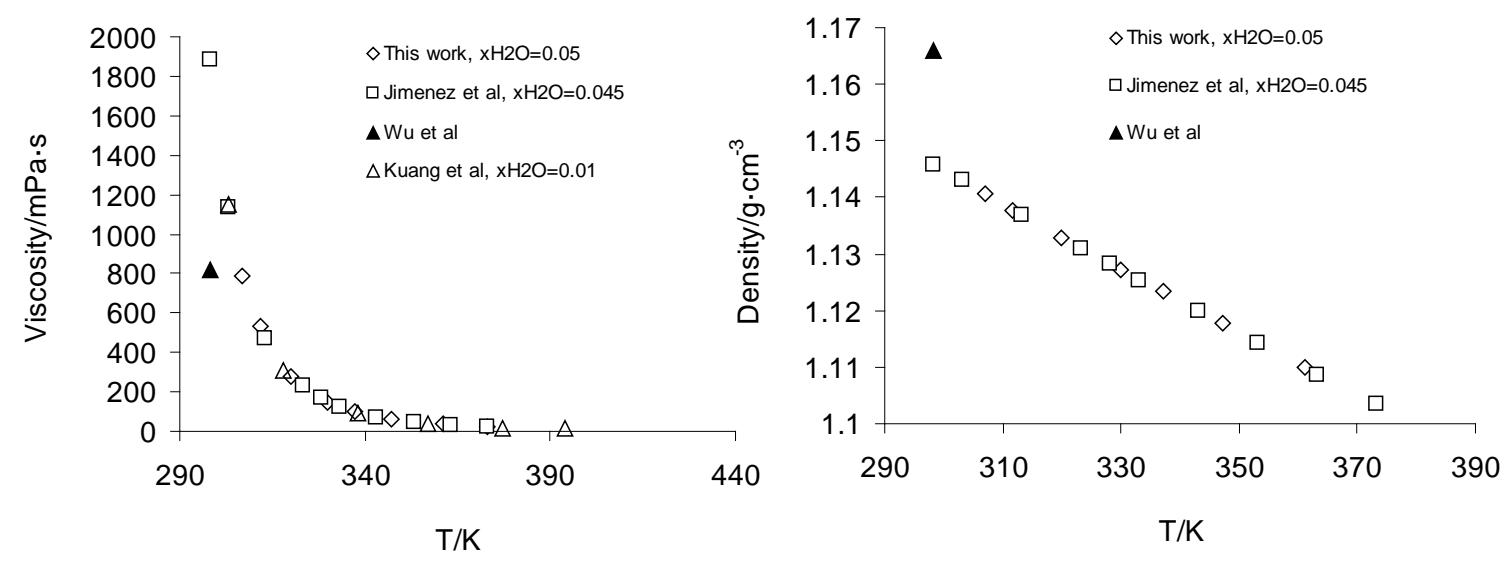

Figure 1. Comparison of viscosity and density measurement of pure 1-allyl-3methylimidazolium chloride measured in this work and literature data [ 20], [ 21], [ 22] 
Experimental densities and viscosities and calculated molar values of the of the mixtures $\mathrm{CO}_{2}+$ AmimCl were listed in Table 2. The $\mathrm{CO}_{2}$ molar fractions were calculated with Group Contribution Equation of State developed by Skold-Jorgensen (GC-EoS) using the parameters fitted in a previous work for mixtures of $\mathrm{CO}_{2}+\mathrm{AmimCl}$ [ 23]. Densities of $\mathrm{CO}_{2}$ at the given temperature and pressure were calculated from NIST data. [24].

Table 2. Densities and viscosities of saturated mixtures $\mathrm{CO}_{2}+1$-allyl3methylimidazolium chloride at different pressures and temperatures

$\begin{array}{cccccc}\text { T/K } & \mathbf{P} / \mathbf{M P a} & \mathbf{X C O 2} & \mathbf{V i s c o s i t y} / \mathbf{m P a} \cdot \mathbf{s} & \mathbf{D e n s i t y} / \mathbf{k g} \cdot \mathbf{m}^{-3} & \mathbf{V}^{\mathrm{Ex}} / \mathbf{c m}^{\mathbf{3}} \mathbf{m o l}^{-\mathbf{1}} \\ 334.7 & 1.0 & 0.054 & 100 & 1125 & -143 \\ 356.6 & 1.0 & 0.039 & 39 & 1113 & -111 \\ 371.5 & 1.0 & 0.032 & 24 & 1104 & -95.8 \\ 368.9 & 4.0 & 0.113 & 24 & 1106 & -74.0 \\ 345.3 & 4.0 & 0.148 & 53 & 1119 & -87.9 \\ 368.7 & 5.8 & 0.152 & 22 & 1106 & -61.8 \\ 337.3 & 5.0 & 0.194 & 72 & 1124 & -80.8 \\ 349.3 & 4.3 & 0.150 & 44 & 1106 & -80.7 \\ 333.6 & 7.2 & 0.251 & 68 & 1126 & -58.7\end{array}$

Viscosity precision $\pm 1 \mathrm{mPa} \cdot \mathrm{s}$ in the range $1-100 \mathrm{mPa} \cdot \mathrm{s}$ and $\pm 10 \mathrm{mPa} \cdot \mathrm{s}$ in the range 100-1000 $\mathrm{mPa} \cdot \mathrm{s}$. Density was determined with a precision of $\pm 1 \mathrm{~kg} \cdot \mathrm{m}^{-3}$. Temperature maximum error of $\pm 0.3^{\circ} \mathrm{C}$. Water molar fraction of AmimCl $\left(\mathrm{x}_{\mathrm{H} 2 \mathrm{O}}=0.497\right)$. Pressure was determined with an accuracy of $\pm 0.1 \mathrm{MPa} . \mathrm{CO}_{2}$ molar fractions calculated using GCEoS. 
It is observed that excess molar volumes present highly negative values, two orders of magnitude more negative than in the case of water + AmimCl mixtures [ 20]. This negative molar volumes are consistent with observed by other authors [13] in different ionic liquids indicate that the $\mathrm{CO}_{2}+\mathrm{AmimCl}$ mixtures present a highly packed structure, as the mixture has a molar volume much lower than this expected for an ideal mixture. This can confirm the theory that $\mathrm{CO}_{2}$ is dissolved in the free spaces of ionic liquids and that the expansion of the ionic liquid inducted by the presence of $\mathrm{CO}_{2}$ is very small [ 13],[ 17], [ 18],[ 19]

\subsection{Correlation of viscosity data}

Viscosity data were correlated with an equation derived from the one used by Seddon et al [5], and that was used by Jimenez et al for correlating viscosity data of aqueous mixtures with several imidazolium chloride mixtures [ 20]. Even when the initial water content of the IL was low, it can strongly affect viscosity, thus, this concentration was taken into account when making the parameterization, introducing a correction of the molar concentration of both $\mathrm{CO}_{2}$ and water, as shown in eq. 1.

$$
\mu / m P a \cdot s=\exp \left(\frac{E}{(T / K)^{2}}+\frac{A}{T / K}+B\right) \cdot \exp \left(\frac{x_{H 2 O}}{C+D \cdot T / K}\right) \cdot \exp \left(\frac{x_{C O 2}}{F+G \cdot T / K}\right)
$$

Where $\mu$ is the viscosity in $\mathrm{mPa} \cdot \mathrm{s}, \mathrm{T}$ is temperature in $\mathrm{K}, \mathrm{x}_{\mathrm{H} 2 \mathrm{O}}$ and $\mathrm{x}_{\mathrm{CO} 2}$ are water and $\mathrm{CO}_{2}$ molar fraction are expressed with relation to the ionic liquid, respectively in $\mathrm{CO}_{2}$ and water free basis. A, B, C, D, E, F, G are empirically obtained parameters. The parameters used for the pure IL (A, B and E) and for the influence of water concentration (C and D) are the same used by Jimenez et al [ 20], and the parameters E and F adjusted to correct viscosity with $\mathrm{CO}_{2}$ concentration were adjusted in this work. Parameterization 
was performed by minimizing the average relative deviation (ARD \%) defined as shown in eq. 2.

$$
A R D \%=\Sigma\left(\frac{\left|\mu_{\exp }-\mu_{\text {calc }}\right|}{\mu_{\exp }}\right)
$$

Adjusted parameters are shown in Table 3. The ARD\% of the equation is of $2.5 \%$ while the maximum deviation with respect to experimental data is $5.7 \%$

Table 3. Parameters fitted to the correlations for calculating the viscosities mixtures $\mathrm{CO}_{2}+\mathrm{H}_{2} \mathrm{O}+1$-allyl-3-methylimidazolium chloride at different . Deviations referred to viscosity.

\begin{tabular}{|c|c|c|}
\hline$\mu / m l$ & $\mathrm{p}\left(\frac{E}{(T / K)^{2}}+\frac{A}{T / K}+B\right) \cdot \exp$ & $\left(\frac{x_{H 2 O}}{C+D \cdot T / K}\right) \cdot \exp \left(\frac{x_{\mathrm{CO} 2}}{F+G \cdot T / K}\right)$ \\
\hline A & -15113 & Jimenez et al [ 20] \\
\hline B & 17.64 & Jimenez et al [ 20] \\
\hline $\mathrm{C}$ & 0.784 & Jimenez et al [ 20] \\
\hline $\mathrm{D}$ & $-3.10 \cdot 10^{-3}$ & Jimenez et al [ 20] \\
\hline $\mathrm{E}$ & 3636000 & Jimenez et al [ 20] \\
\hline $\mathrm{F}$ & $3.731 \pm 0.015$ & This work \\
\hline G & $-1.255 \cdot 10^{-2}$ & This work \\
\hline ARD\% & $2.5 \%$ & \\
\hline Max. Dev. & $5.7 \%$ & \\
\hline
\end{tabular}


The predicted viscosities of several $\mathrm{CO}_{2}+\mathrm{AmimCl}$ mixture with low water concentration and water free predicted by the correlation are plotted in Figure 2 as a function of pressure and of $\mathrm{CO}_{2}$ molar fraction. Please note that the molar fractions in the ionic liquid corresponding to a given P,T data were calculated with the GC-EoS [ 23]. It is observed that $\mathrm{CO}_{2}$ can reduce the viscosity of the $\mathrm{AmimCl}$ up to $43 \%$ at $60^{\circ} \mathrm{C}$ and $7.5 \mathrm{MPa}$ and molar fractions of 0.25 of $\mathrm{CO}_{2}$ with respect to the ionic liquid. At higher temperatures the effect of $\mathrm{CO}_{2}$ in viscosity is lower i.e. at $95^{\circ} \mathrm{C}$, the pressure necessary to have a molar fraction of 0.25 in the ionic liquid is of $13 \mathrm{MPa}$, and the viscosity is reduced only a $25 \%$ with respect the viscosity of the pure ionic liquid.
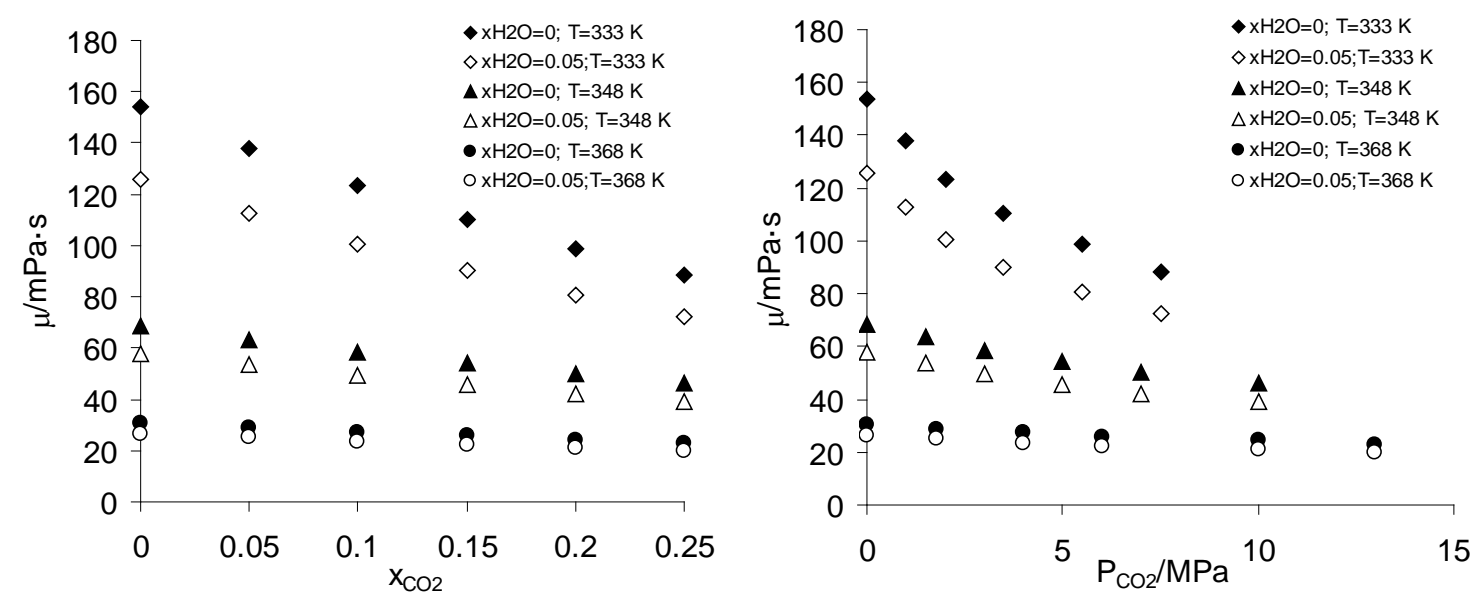

Figure 2. Viscosity predicted by the correlation as a function of $\mathrm{CO}_{2}$ molar fraction and $\mathrm{CO}_{2}$ pressure for different temperatures and initial water concentrations of the ionic liquid AmimCl

To test the validity of this correlation with other $\mathrm{CO}_{2}+\mathrm{IL}$ mixtures, literature viscosity data were correlated for several $\mathrm{CO}_{2}+$ ionic liquids mixtures using literature data: 1butyl-3-metylimidazolium tetrafluoroborate $\quad\left(\right.$ bmimBF$\left._{4}\right) \quad[\quad 8] ; \quad:$ 1-butyl-3metylimidazolium hexafluorophosphate (bmimPF 6$)$ [ 9]; 1-hexyl-3-metylimidazolium 
hexafluorophosphate (hmimPF6) [ 10],[ 25], [ 26] ; 1-octyl-3-metylimidazolium hexafluorophosphate (omimPF 6 ) [ 10],[ 26],[ 27]; 1-ethyl-3-metylimidazolium trifluoromethylsulfonylimide $\left(\mathrm{emimTf}_{2} \mathrm{~N}\right)$ [ 12], [ 28]; 1-hexyl-3-metylimidazolium trifluoromethylsulfonylimide $\left(\mathrm{hmimTf}_{2} \mathrm{~N}\right)$ [ 12], [ 29] and 1-decyl-3-metylimidazolium trifluoromethylsulfonylimide $\left(\operatorname{dmimTf}_{2} \mathrm{~N}\right)$ [ 12], [ 30]. Parameters adjusted, ARDs and maximum deviations from experimental data are presented in Table 4. Viscosities can be predicted with average deviations from 4 to $13 \%$ and maximum deviations from 15 to $46 \%$.

Table 4. Parameters fitted to the correlations for calculating the viscosities mixtures $\mathrm{CO}_{2}+$ IL for the ILs: bmimBF 4 [ 8]; bmimPF 6 [ 9]; hmimPF [ [ 10],[ 25], [ 26] ; $\operatorname{omimPF}_{6}$ [ 10],[ 26],[ 27]; emimTf $2 \mathrm{~N}$ [ 12], [ 28]; $\operatorname{hmimTf}_{2} \mathrm{~N}$ [ 12], [ 29] and $\operatorname{dmimTf}_{2} \mathrm{~N}[12],[30]$

$$
\mu / m P a \cdot s=\exp \left(\frac{E}{(T / K)^{2}}+\frac{A}{T / K}+B\right) \cdot \exp \left(\frac{x_{C O 2}}{F+G \cdot T / K}\right)
$$

\begin{tabular}{lccccccc}
\hline Parameters & bmimBF $_{4}$ & bmimPF $_{6}$ & hmimPF $_{\mathbf{6}}$ & omimPF $_{\mathbf{6}}$ & $\mathbf{e m i m T f}_{\mathbf{2}} \mathbf{N}$ & $\mathbf{h m i m T f}_{2} \mathbf{N}$ & $\mathbf{d m i m T f}_{2} \mathbf{N}$ \\
\hline A & -4260 & -4690 & -6950 & -6320 & -3980 & -2300 & -4700 \\
\hline B & 4.03 & 4.59 & 7.62 & 6.39 & 4.68 & 1.44 & 4.90 \\
\hline E & 1330950 & 1508250 & 1945200 & 1902000 & 1079740 & 936800 & 1390300 \\
\hline F & 1.17 & 0.698 & 0.7337 & 0.621 & 1.632 & 0.968 & 1.006 \\
\hline G & $-4.74 \cdot 10^{-3}$ & $-3.02 \cdot 10^{-3}$ & $-3.20 \cdot 10^{-3}$ & $-3.02 \cdot 10^{-3}$ & $-6.65 \cdot 10^{-3}$ & $-4.30 \cdot 10^{-3}$ & $-4.26 \cdot 10^{-3}$ \\
\hline ARD \% & $4.6 \%$ & $4.5 \%$ & $4.4 \%$ & $8.3 \%$ & $6.4 \%$ & $13 \%$ & $6.2 \%$ \\
\hline Max Dev & $16 \%$ & $15 \%$ & $26 \%$ & $29 \%$ & $27 \%$ & $46 \%$ & $35 \%$ \\
\hline
\end{tabular}

[10],[25],

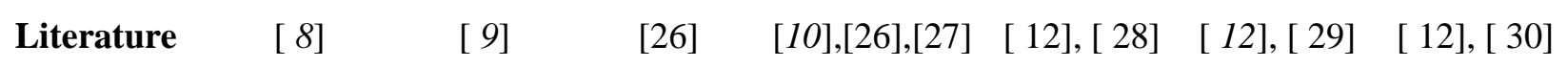


In figure 3 predicted viscosity of mixtures $\mathrm{CO}_{2}+\mathrm{IL}$ are compared to experimental data is shown. A good reproducibility of the experimental data is observed.
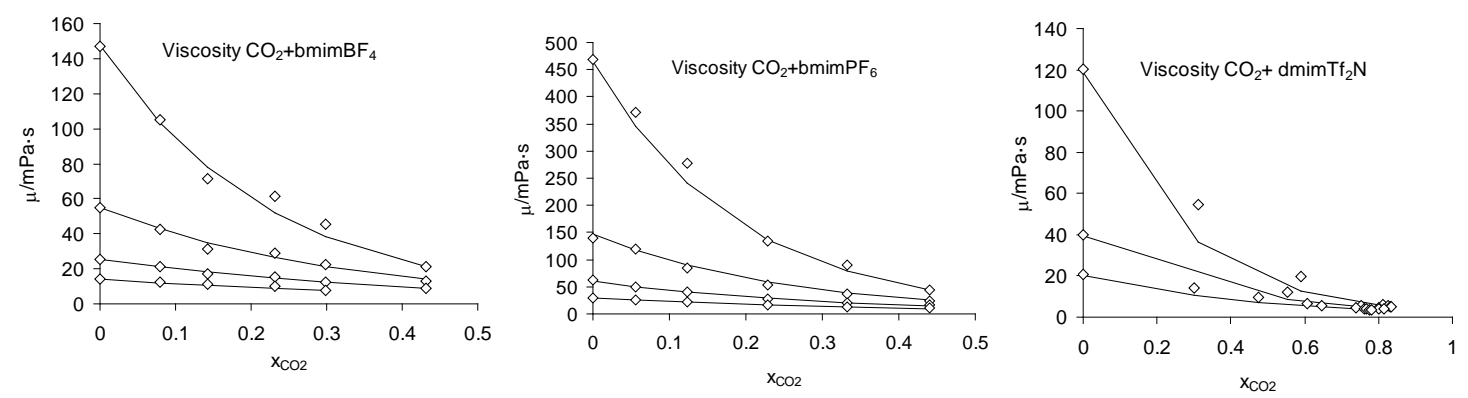

Figure 3. Comparison of the viscosity predicted by the model and the experimental data for the mixtures $\mathrm{CO}_{2}+\mathrm{IL}$ : $\operatorname{bmimBF}_{4}$ [ 8]; : bmimPF 6 [9]; and $\operatorname{dmimTf}_{2} \mathrm{~N}[12]$, [ 30]. Symbols represent the experimental data and lines represent the predictions of the model.

In figure 4 the percentage of viscosity reduction vs molar fraction of $\mathrm{CO}_{2}$ with respect to the viscosity of the pure Il at the same temperature is plotted for some ionic liquids of the different families considered in this work, at 333 and at $293 \mathrm{~K}$. It is observed that viscosity reduced linearly with $\mathrm{CO}_{2}$ molar fraction until reached a certain concentration of $\mathrm{CO}_{2}$ beyond which the reduction of $\mathrm{CO}_{2}$ is lower. The viscosity reduction can reach between $60-90 \%$ depending on the ionic liquid and it is more pronounced at lower temperatures.
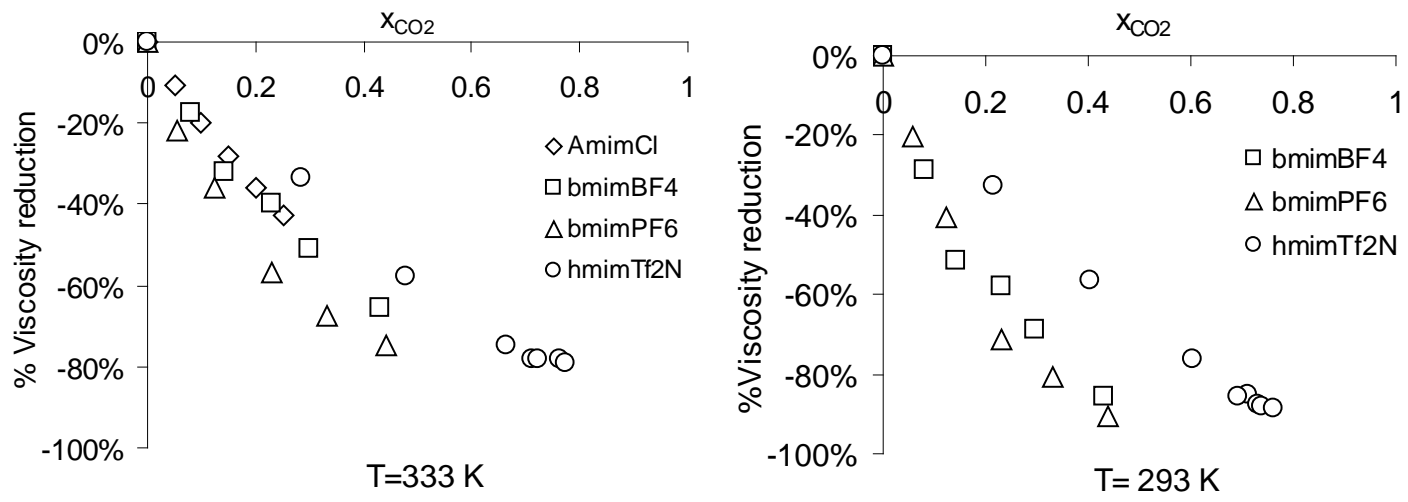
Figure 4. Percentage of viscosity reduction with CO2 molar fraction for the ionic liquids $\operatorname{bmimBF}_{4}$ [9], bmimPF 6 [10], hmimTf $2 \mathrm{~N}$ [ 12] and $\mathrm{AmimCl}$ at 333 and $293 \mathrm{~K}$.

\section{Conclusions}

The viscosities and densities of the pure ionic liquids 1-allyl-3-methylimidazolium choride (AmimCl) have been experimentally determined as well as for mixtures $\mathrm{CO}_{2}+$ AmimCl with molar fractions up to 0.25 and temperatures in the range 333-372 K.

Densities were used to calculate excess molar values, that resulted strongly negative with values -60 and $-140 \mathrm{~cm}^{3} / \mathrm{mol}$, being less negative at higher temperatures and CO2 molar fractions. This indicates that the $\mathrm{CO}_{2}+\mathrm{AmimCl}$ mixtures present a highly packed structure and can confirm the generally accepted theory that $\mathrm{CO}_{2}$ is dissolved in the free spaces of ionic liquids and that the expansion of the ionic liquid inducted by the presence of $\mathrm{CO}_{2}$ is very small.

Viscosities were correlated as a function of temperature and carbon dioxide molar fractions with an average relative error of $2.5 \%$. The viscosities of other mixtures $\mathrm{CO}_{2}+$ ionic liquids were also correlated for ionic liquids of the families imidazolium tetrafluoroborate, imidazolium hexafluorophosphate and imidazolium trifluoromethylsulfonylimide with an average error between 4.4 and $13 \%$.

In general AmimCl and the other ionic liquids present a linear decrease of viscosity with $\mathrm{CO}_{2}$ molar fractions up to around 0.5 mol that more pronounced at lower temperatures and depends of each ionic liquid, and can reach between $60-100 \%$ viscosity reduction with respect the viscosity of the pure ionic liquid, making the $\mathrm{CO}_{2}$ a promising cosolvent for viscosity reduction in process with ionic liquids. 


\section{Acknowledgments}

Authors thank the Marie Curie Program for the Project DoHip “Training program for the design of resource and energy efficient products for high pressure process”, the Junta de Castilla y León for funding through the project VA295U14 . MDB and AM thank the Spanish Ministry of Economy and Competitiveness for the Ramón y Cajal research fellowships. E. Weidner wishes to thank the Cluster of Excellence RESOLV (EXC 1069) funded by the Deutsche Forschungsgemeinschaft for the support.

\section{References}

[ 1] A. Pinkert, K.N. Marsh, S. Pang, M.P. Staiger, Ionic liquids and their interaction with cellulose, Chemical Reviews 109 (2009) 6712-6728. doi:10.1021/cr9001947.

[ 2] H. Cruz, M. Fanselow, J.D. Holbrey, K.R. Seddon KR, Determining relative rates of cellulose dissolution in ionic liquids through in situ viscosity measurement, Chemical Communications 48 (2012) 5620-5622. doi:10.1039/C2CC31487H

[ 3] S. Morales de la Rosa, J.M. Campos-Martin, J.L.G. Fierro, High glucose yields from the hydrolysis of cellulose dissolved in ionic liquids, Chemical Engineering J. 181-182 (2012) 538-541. doi:10.1016/j.cej.2011.11.061.

[ 4] K.R. Seddon, A. Stark, M.J. Torres, Influence of chloride, water, and organic solvents on the physical properties of ionic liquids, Pure and Applied Chemistry 72 (2000) 2275-2287. doi:10.1351/pac200072122275.

[ 5] L.A. Blanchard, D. Hancu, E.J. Beckman, J.F. Brennecke, Green processing using ionic liquids and $\mathrm{CO}_{2}$, Nature. 399 (1999) 28-29. doi:10.1038/19887. 
[ 6] S. Raeissi, C.J. Peters, Carbon dioxide solubility in the homologous 1-alkyl-3methylimidazolium bis(trifluoromethylsulfonyl)imide family, J. of Chemical \& Engineering Data 54 (2009) 382-386. doi:10.1021/je800433r.

[ 7] S. Jang, D.-W. Cho, T. Im, H. Kim, High-pressure phase behavior of $\mathrm{CO}_{2}+1$-butyl3-methylimidazolium chloride system, Fluid Phase Equilibria 299 (2010) 216-221. doi:10.1016/j.fluid.2010.09.039.

[ 8] D. Tomida, A. Kumagai, K. Qiao, C. Yokoyama, Viscosity of 1-butyl-3methylimidazolium tetrafluoroborate $+\mathrm{CO}_{2}$ mixture, High Temp. (Engl. Transl.) 37 (2008) 81-89.

[ 9] D. Tomida, A. Kumagai, K. Qiao, C. Yokoyama, C. , Viscosity of 1-Butyl-3methylimidazolium Hexafluorophosphate + CO2 Mixture J. Chem. Eng. Data 52 (2007) 1638-1640.

[10] D. Tomida, S. Kenmochi, K. Qiao, Q. Bao, C. Yokoyama, C. Viscosity of ionic liquid mixtures of 1-alkyl-3-methylimidazolium hexafluorophosphate $+\mathrm{CO}_{2}$, Fluid Phase Equilibria 307(2011) 185-189

[ 11] Z. Liu, W. Wu, B. Han, Z. Dong, G. Zhao, J. Wang, T. Jiang, G. Yang, (2003) Study on the Phase Behaviors, Viscosities, and Thermodynamic Properties of $\mathrm{CO}_{2} /\left[\mathrm{C}_{4} \mathrm{mim}\right]\left[\mathrm{PF}_{6}\right] /$ methanol system at Elevated Pressures, Chemistry -A European J. 9 (2003) 3897-3903.

[ 12] A. Ahosseini, E. Ortega, B. Sensenich, A.M. Scurto, Viscosity of n-alkyl-3methyl-imidazolium bis(trifluoromethylsulfonyl)amide ionic liquids saturated with compressed $\mathrm{CO}_{2}$, Fluid Phase Equilib. 286 (2009) 72 -78 
[ 13] P.J. Carvalho, T. Regueira, J. Fernandez, L. Lugo, J. Safarov, E. Hassel, J.A.P.

Coutinho, High pressure density and solubility for the $\mathrm{CO}_{2}+1$-ethyl-3-

methylimidazolium ethylsulfate system J. Supercritical Fluids 88 (2014) 46-55.

[14] S. N. V. K. Aki, B.R. Mellein, E. Saurer, J.F. Brennecke, High-Pressure Phase Behavior of Carbon Dioxide with Imidazolium-Based Ionic Liquids J. Physical Chemistry B 108 (2004) 20355-20365

[ 15] I. Mejia, K. Stanley, R. Canales, J. Brennecke, On the High-Pressure Solubilities of Carbon Dioxide in Several Ionic Liquids, J. Chem. Eng. Data 58 (2013), 2642-2653

[ 16] D. Kodama, M. Kanakubo , M. Kokuboa, T. Onoa, H. Kawanamib, T. Yokoyama, H. Nanjo, M. Kato, $\mathrm{CO}_{2}$ absorption properties of Brønsted acid-base ionic liquid composed of N,N-dimethylformamide and bis(trifluoromethanesulfonyl)amide, J. Supercritical Fluids, 52 (2010) 189-192

[17] W. Shi, E.J. Maginn, Atomistic simulation of the absorption of carbon dioxide and water in the ionic liquid 1-n-hexyl-3-methylimidazolium bis(trifluoromethylsulfonyl)imide ([hmim][Tf 2 N]), J. Physical Chemistry B 112 (2008) 2045-2055.

[ 18] X. Huang, C.J. Margulis, Y. Li, B.J. Berne, Why is the partial molar volume of $\mathrm{CO}_{2}$ so small when dissolved in a room temperature ionic liquid? Structure and dynamics of $\mathrm{CO}_{2}$ dissolved in $\left[\mathrm{Bmim}^{+}\right]\left[\mathrm{PF}^{-}\right]$, J. American Chemical Society 127 (2005) $17842-17851$

[ 19] M.I. Cabac , M. Besnard, Y. Danten, J.A.P. Coutinho, Solubility of $\mathrm{CO}_{2}$ in 1butyl-3-methyl-imidazolium-trifluoro acetate ionic liquid studied by Raman spectroscopy and DFT investigations, J. Physical Chemistry B 115 (2011) 3538-3550. 
[ 20] C. Jiménez de la Parra, J. R. Zambrano, M. D. Bermejo, Á. Martín, J. J. Segovia, M. J. Cocero, Influence of water concentration in the viscosities and densities of cellulose dissolving ionic liquids. J Chemical Thermodynamics 91 (2015) 8-16

[ 21] Q. Kuang, J. Zhang, Z. Wang, Revealing Long-Range Density Fluctuations in Dialkylimidazolium Chloride Ionic Liquids by Dynamic Light Scattering, J. Physical Chemistry B 111(2007) 9858-9863

[ 22] D. Wu, B. Wu, Y. M. Zhang, H. P. Wang, Density, Viscosity, Refractive Index and Conductivity of 1-Allyl-3-methylimidazolium Chloride + Water Mixture, J. Chemical Engineering Data, 55 (2010) 621-624

[ 23] J. M. Lopes, F. A. Sánchez, S. B. Rodríguez Reartes, M. D. Bermejo, Á. Martín, M. J.Cocero, Melting point depression effect with $\mathrm{CO}_{2}$ in high melting temperature cellulose dissolving ionic liquids. Modeling with group contribution equation of state, $\mathrm{J}$. Supercritical Fluids (In Press) 2015

[ 24] http://webbook.nist.gov/chemistry/ (last accessed $9^{\text {th }}$ October 2015)

[ 25] K.R. Harris, M. Kanakubo, L. A. Woolf, Temperature and Pressure Dependence of the Viscosity of the Ionic Liquids 1-Hexyl-3-methylimidazolium Hexafluorophosphate and 1-Butyl-3-methylimidazolium Bis(trifluoromethylsulfonyl)imide, J. Chemical Engineering Data 52 (2007) 1080-1085

[ 26] D. Tomida, A. Kumagai, S. Kenmochi, K. Qiao, C. Yokoyama, Viscosity of 1Hexyl-3-methylimidazolium Hexafluorophosphate and 1-Octyl-3-methylimidazolium Hexafluorophosphate at High Pressure J. Chemical Engineerin Data 52 (2007) 577-579

[ 27] K.R. Harris, M. Kanakubo, L.A. Woolf, Temperature and Pressure Dependence of the Viscosity of the Ionic Liquids 1-Methyl-3-octylimidazolium Hexafluorophosphate 
and 1-Methyl-3-octylimidazolium Tetrafluoroborate, J. Chemical Engineering Data 51 (2006) 1161-1167

[ 28] C. Schreiner, S. Zugmann, R. Hartl, H.J. Gores, Fractional Walden Rule for Ionic Liquids: Examples from Recent Measurements and a Critique of the So-Called Ideal KCl Line for the Walden Plot, J. Chemical Engineering Data 55 (2010) 1784-1788

[ 29] M.E. Kandil, K.N. Marsh, A.R.H. Goodwin, Measurement of the Viscosity, Density, and Electrical Conductivity of 1-Hexyl-3-methylimidazolium Bis(trifluorosulfonyl)imide at Temperatures between (288 and 433) $\mathrm{K}$ and Pressures below 50 MPa, J. Chemical Engineering Data 52 (2007) 2382-2387

[ 30] M. Tariq, P. Carvalho, J.A.P. Coutinho, I.M. Marrucho, J.N.C. Lopes, L.P.N. Rebelo, Viscosity of (C2-C14) 1-alkyl-3-methylimidazolium bis(trifluoromethylsulfonyl)amide ionic liquids in an extended temperature range, Fluid Phase Equilibria 301 (2011) 22-3 